\title{
Affective reactions to auditory hallucinations in psychotic, evangelical and control groups
}

\author{
Martin F. Davies*, Murray Griffin and Sue Vice \\ Goldsmiths College, University of London, UK
}

\begin{abstract}
Objectives. Building on recent work on the similarities and differences in delusional ideation between psychotic and religious populations (Peters, Day, McKenna, \& Orbach, 1999), the experiences of auditory hallucinations in psychotic, evangelical and control groups were examined in this study.
\end{abstract}

Method. The incidence and subjective experiences of hearing voices were assessed using questionnaire methods in psychotic out-patients, evangelical Christians and controls (non-psychotic, non-evangelical).

Results. Incidence of auditory hallucinations differed significantly across the three groups with psychotics showing the highest levels and controls the lowest levels. The experiences of the evangelical group were significantly more positive than those of the control group, which in turn were significantly more positive than those of the psychotic group. The most recent experience of hearing voices was rated more positively than the first experience by the psychotic and religious groups but not by the control group. These findings were much stronger for affective reactions to the experiences than for perceptions of the voices.

Conclusion. These results provide only partial support for the findings of Peters et al. (1999) on differences in delusional ideation and possible reasons for this are discussed. The findings for religious and psychotic individuals are discussed further in terms of interpretational and coping mechanisms.

The term 'hallucination' has been defined as a sensory perception without external stimulation of the relevant sensory organ (DSM-III-R; American Psychiatric Association, 1987). Hallucinations are complex and varied, and can affect each of the five senses, but most research has been devoted to auditory hallucinations. Psychologists have long regarded hallucinations as indicators of serious psychological disturbance (e.g. Esquirol, 1832; Heilbrun, 1980; Jaspers, 1911; Schneider, 1959). However, humankind has been familiar with hallucinatory experiences for even longer, at least since biblical times (Preuss, 1975). The originators of major monotheistic religions (e.g. Moses, Jesus, Mohammed) were all reported to have heard voices not apparent to others. In those days,

* Requests for reprints should be addressed to Dr Martin F. Davies, Psychology Department, Goldsmiths College, University of London, New Cross, London SE14 6NW, UK (e-mail: psa01mfd@gold.ac.uk). 
such experiences were seen as divine, but nowadays hallucinations are generally regarded as an important symptom of schizophrenia (e.g. DSM-III-R). However, in contrast to this prevailing view of hallucinations as symptoms of psychopathology and illness, there is an important school of thought in psychology and psychiatry, beginning with William James (1902), which argues that hallucinations can be non-pathological and adaptive experiences (see Fulford, 1989; Jackson \& Fulford, 1997).

There have been numerous explanations for hallucinations, including imagery (Mintz \& Alpert, 1972), conditioning (Hefferline, Bruno, \& Camp, 1971), the seepage of preconscious material into consciousness (West, 1962), inter-hemispheric transfer of information (Green \& Preston, 1981), impairment of neurological mechanisms of inner speech (Johnson, 1979) and a disorder of discourse planning (Hoffman, 1986). Although there is no comprehensive model that explains the occurrence of auditory hallucinations, current accounts emphasize the importance of cognitive factors, in particular, the misattribution of internal cognitive events to external sources (e.g. Bentall, 1990; Slade \& Bentall, 1988). This misattribution may be due to deficits in cognitive functioning (e.g. David, 1994; Frith, 1992; Hemsley, 1993) or to biases in normal functioning (e.g. Bentall, 1990; Morrison \& Haddock, 1997). With respect to the latter explanation, it appears that the predisposition to hallucinate is not an all or nothing affair but one based on a continuum of probability (e.g. Bentall \& Slade, 1985). This mirrors research on psychoticism, which shows that psychosis is not separate from normality but is merely an extreme along a continuum of normality-abnormality (Eysenck, 1992). According to Claridge $(1985,1994)$, psychotic characteristics are not the prerogative of the classically psychotic patient, rather there is a continuity of behaviour blending into a spectrum of illness. Not surprisingly, therefore, studies of normal populations have found that between 10 and $37 \%$ of people report having experienced auditory hallucinations (e.g. Barrett \& Etheridge, 1992; Bentall \& Slade, 1985; Morrison, Wells, \& Nothard, 2000).

Across cultures, the experience of hallucinations varies a great deal (e.g. Al-Issa, 1978; Andrade, 1988). In most Western cultures, hallucinations tend to be regarded as threatening, whereas in non-Western cultures, hallucinations can be regarded as sacred experiences (e.g. Prince, 1992). This distinction corresponds to the difference between psychological and religious interpretations of hallucinations (e.g. Bhugra, 1996). Whereas the psychological literature views hallucinations as pathological afflictions, the religious literature views some hallucinatory experiences as holy and transcendent (although other experiences may be regarded as the opposite, such as demonic possession) (e.g. Hood, 1973).

In keeping with the cognitive approach to hallucinations in terms of attributions and beliefs, recent research has emphasized the importance of studying the subjective experience of hearing voices rather than simply the frequency or content of voices (e.g. Chadwick \& Birchwood, 1994; Close \& Garety, 1998; Jackson \& Fulford, 1997). For example, Chadwick and Birchwood (1994) found in schizophrenic patients that voices perceived to be malevolent provoked negative emotions and were resisted, whereas voices perceived to be benevolent provoked positive emotions and were engaged. Beliefs about the voices were not always linked to voice content (in $31 \%$ of cases beliefs were incongruous with content) and were based more closely on the identity and meaning of the voices. (Contrary to Chadwick \& Birchwood, however, Close \& Garety (1998) found that beliefs about malevolence/benevolence were always related to voice content in their 
sample of schizophrenic patients.) Although research on psychotic patients has found that there can be positive effects of hallucinations (e.g. Miller, O'Connor, \& Di Pasquale, 1993), the typical psychotic perception of voices is malevolence and the typical reaction is one of negative affect and distress (e.g. Garety \& Hemsley, 1987, 1994).

The picture is less clear with respect to religious samples. On the one hand, some studies have found that psychotic and mystical states show many similarities in terms of delusions and hallucinations. For example, Jackson (1997) found no clear borderline differentiating psychotic and spiritual experiences. On the other hand, there appear to be differences in terms of the meaning and interpretation attributed to psychotic vs. spiritual experiences and also in terms of the emotional and behavioural reactions to such experiences. Spiritual experiences can have adaptive and life-enhancing consequences, whereas psychotic experiences lead to negative social and behavioural consequences (Fulford, 1989). In a recent study, Peters, Day, McKenna, and Orbach (1999) found evidence to support both these viewpoints. Peters et al. found that individuals belonging to cults or new religious movements (Druids and Hare Krishnas) scored significantly higher on incidence of delusional ideation than control groups (nonreligious and Christian), but they did not differ significantly from psychotic in-patients. However, these religious individuals showed levels of distress associated with their delusions that were significantly lower than psychotic in-patients and more akin to those shown by the control groups.

Comparative research on psychotic, religious and normal samples relating to psychosis and schizotypy has thus far been carried out mainly with reference to delusional beliefs and experiences. The present study set out to examine the more specific experience of auditory hallucinations as a function of psychoticism and religiosity. Compared with 'normal' controls, it was expected that psychotic individuals would perceive hallucinations as more negative because the typical psychotic auditory hallucination involves malevolent voices (e.g. Chadwick \& Birchwood, 1994; Close \& Garety, 1998). However, it was expected that religious individuals, specifically evangelical Christians, ${ }^{1}$ would experience hallucinations as more positive than controls, because the typical evangelical experience of an auditory hallucination is interpreted in terms of benign or even divine intervention (e.g. Buckley \& Galanter, 1979; Jackson, 1997).

\section{Method}

\section{Participants}

Following an initial screening based on biographical and demographic information, participants in the three groups were selected on a matching basis such that there were no significant differences between the groups on gender ratio, age, ethnicity (Black/White) and years of education.

The psychotic group (mean age 32.56 years) was composed of 7 men and 11 women who had been diagnosed as suffering from schizophrenia (but which was currently in remission) and who reported never having been a born-again Christian or a member of an evangelical Christian church. The evangelical group (mean age 33.28 years) was composed of 9 men and 20 women who regarded themselves as bornagain Christians, who were members of evangelical Christian churches, and who reported no previous treatment for mental illness. The control group (mean age 33.02 years) was composed of 20 men and 35

\footnotetext{
${ }^{1}$ Evangelical Christians rather than just religious people were selected as a comparison group because of the importance of spiritual experiences and spiritual rebirth in these religious denominations.
} 
women who reported no previous treatment for mental illness and who had never been a born-again Christian or a member of an evangelical Christian church.

\section{Materials}

The first part of data collection involved the administration of a biographical/demographic questionnaire and the Launay-Slade measure of predisposition to hallucinate (Launay \& Slade, 1981). In the second part, those participants who responded affirmatively to the question whether or not they had ever experienced hearing a voice outside the head when no one was present completed further questionnaires including reported frequency of hearing voices, affective experiences of hearing voices and perception of voices (these latter two questionnaires were especially devised for the present study following pilot testing).

The Launay-Slade inventory consists of 12 statements describing hallucinatory experiences to which respondents indicate their applicability using 5 -point Likert scales $(0=$ certainly does not apply to me; 4 = certainly applies to me).

The Affective Experiences questionnaire assessed participants' feelings during and immediately after their first and after their most recent experience of hearing a voice. The questionnaire consisted of 12 bipolar rating scales (Cronbach's $\alpha=.71$ ): scared-unafraid, sad-happy, confused-clearheaded, cursedblessed, depressed-elated, numbed-exhilarated, doubting-believing, agitated-calm, invaded-welcomed, hazy-alert, nervous-confident, possessed-in control.

The Perception of Voices questionnaire assessed participants' perceptions of the voice during their first and most recent experience of hearing a voice. The questionnaire consisted of 16 bipolar rating scales (Cronbach's $\alpha=.77$ ): hostile-amiable, rude-polite, sad-happy, evil-good, disdainful-approving, tormenting-comforting, destructive-constructive, lifeless-animated, cold-emotional, scornful-kindly, stern-tender, ignorant-knowing, standoffish-intimate, repulsive-seductive, false-genuine, shockingsoothing.

Participants made their ratings on 8-point scales. The ratings were scored such that a higher score indicates a more positive evaluation.

\section{Procedure}

Participants in the psychotic group were recruited from day centres for people with mental health problems. Participants in the evangelical group were recruited mainly from people attending evangelical Christian churches. Those in the control group were recruited from non-academic staff in various educational establishments in south-east London.

Once permission had been obtained to approach members of each group, the researchers spent time with each participant within each setting in order to gain their trust, to collect data, and to talk informally about their experiences if they so wished. Owing to the nature of the research, it was necessary to reassure participants that they could be honest and not just give publicly acceptable answers. Questionnaires were completed anonymously but participants could seek clarification from the researchers if required. Participants were assured of complete confidentiality and the option to withdraw themselves and/or their data from the study at any time.

\section{Results}

The percentage of people hearing voices and the mean scores on the Launay-Slade hallucination scale are shown in Table 1 . As can be seen from Table 1, the psychotic group was more likely to report hearing voices and scored higher on the Launay-Slade scale than the evangelical group, which in turn was more likely to report hearing voices and scored higher on the Launay-Slade scale than the control group. Note that frequency of hearing voices could not be analysed straightforwardly because most of those in the psychotic group (14 of 18) and some of those in the evangelical group (7 of 17) could not assign a numerical value to how often they had experienced voices and responded 'all 
the time' (no one in the control group gave this response). However, a $\chi^{2}$ analysis showed that the proportion of those responding 'all the time' differed significantly as a function of group, $\chi^{2}(2)=20.33, p<.001$, such that the psychotic group gave this response more than the evangelical group $(p<.05)$ who in turn gave this response more than the control group $(p<.01)$.

Table 1. Percentage of people hearing voices and Launay-Slade scores for psychotic, evangelical and control groups

\begin{tabular}{lccc}
\hline & \multicolumn{3}{c}{ Group } \\
\cline { 2 - 4 } Measure & $\begin{array}{c}\text { Control } \\
(N=55)\end{array}$ & $\begin{array}{c}\text { Evangelical } \\
(N=29)\end{array}$ & $\begin{array}{c}\text { Psychotic } \\
(N=18)\end{array}$ \\
\hline Percentage hearing voices & $27.27_{\mathrm{A}}$ & $58.62_{\mathrm{B}}$ & $100.00_{\mathrm{C}}$ \\
Launay-Slade score $M$ & $15.20_{\mathrm{A}}$ & $21.69_{\mathrm{B}}$ & $39.61_{\mathrm{C}}$ \\
SD & 7.68 & 7.80 & 5.92 \\
\hline
\end{tabular}

Note. Within rows, those numbers not sharing the same subscript are significantly different at the .01 level (for hearing voices, overall $\chi^{2}(2)=30.2, p<.001$; for Launay-Slade scores, overall $F(2,101)=72.97$, $p<.001)$.

Table 2. Mean rated feelings and perceptions of voices for psychotic, evangelical and control groups

\section{Group}

\begin{tabular}{lccc}
\cline { 2 - 4 } Measure & $\begin{array}{c}\text { Control } \\
(N=15)\end{array}$ & $\begin{array}{c}\text { Evangelical } \\
(N=17)\end{array}$ & $\begin{array}{c}\text { Psychotic } \\
(N=18)\end{array}$ \\
\hline Rated feelings & & & \\
$\quad$ During first experience & 5.87 & 6.50 & 4.54 \\
During last experience & 5.73 & 6.95 & 5.36 \\
After first experience & 5.70 & 6.63 & 4.40 \\
After last experience & 5.60 & 7.03 & 5.22 \\
Perception of voice & & & \\
During first experience & 6.03 & 6.74 & 4.96 \\
During last experience & 5.99 & 6.94 & 5.33 \\
\hline
\end{tabular}

Note. Higher scores indicate a more positive evaluation.

The affective reactions of those hearing voices are shown in Table 2. Rated feelings were analysed using a 3 (group) $\times 2$ (during/after the experience) $\times 2$ (first/last experience) ANOVA with repeated measures on the last two factors. Overall, there was a highly significant main effect of group, $F(2,47)=12.00, p<.001$. The evangelical group gave the highest ratings $(M=6.78)$, whereas the psychotic group gave the lowest ratings $(M=4.88)$ with the control group in between $(M=5.72)$. Planned contrasts 
showed that the rated feelings of the evangelical group were significantly more positive than those of the control group, $t(47)=2.59, p<.02$, which in turn were significantly more positive than those of the psychotic group, $t(47)=2.11, p<.05$.

In addition to this main effect of group, there was also a significant main effect of first/last experience, $F(1,47)=9.30, p<.005$, such that the last experience was rated more positive $(M=5.98)$ than the first experience $(M=5.58)$. However, this main effect was qualified by an interaction with group, $F(2,47)=4.78, p<.02$. The basis of this interaction is that the last experience was rated much more positive than the first experience by the psychotic group, simple effect $F(1,47)=16.09, p<.001$, less so for the evangelical group, simple effect $F(1,47)=4.03, p<.05$, whereas for the control group the last experience was rated slightly but nonsignificantly less positive than the first experience. One possible explanation for these unexpected findings is that the evangelical and psychotic groups have had considerably more experiences of hearing voices and have adapted or habituated to it (possibly through the use of some coping mechanisms). The control group has had considerably less experience (in some cases only one experience $)^{2}$ and has not habituated to it. For this group, a recency effect may apply such that the most recent experience is more vivid than the first experience.

Perceptions of voices were analysed using a 3 (group) $\times 2$ (first/last experience) ANOVA with repeated measures on the last factor. Again, there was a highly significant main effect of group, $F(2,47)=9.90, p<.001$. The evangelical group gave the highest ratings $(M=6.84)$, whereas the psychotic group gave the lowest ratings $(M=5.15)$ with the control group in between $(M=6.01)$. Planned contrasts showed that the perceptions of the evangelical group were significantly more positive than those of the control group, $t(47)=2.08, p<.05$, which in turn were significantly more positive than those of the psychotic group, $t(47)=2.20, p<.05$. As can be seen from Table 2 , perceptions of voices were rated more positive for the last experience $(M=6.08)$ than for the first experience $(M=5.89)$, but this main effect did not reach significance, $F$ $(1,47)=2.52, p=.12$. Again, this effect was shown by the evangelical and psychotic groups but not by the control group.

\section{Discussion}

The findings of the present study show that reported occurrence of hallucinations (as measured by likelihood of hearing voices and Launay-Slade scores) increased significantly from normal controls through evangelical Christians to psychotic individuals. Although likelihood of hallucinations reliably discriminates between psychotic and normal populations (cf. DSM-III-R; American Psychiatric Association, 1987), it is certainly not the case that auditory hallucinations are unique to psychotic individuals; $27 \%$ of individuals in the 'normal' control group reported hearing voices. ${ }^{3}$ Also, it is not the case in the present study that people's experience of auditory hallucinations is markedly negative. In fact, the mean ratings of both the experience of

\footnotetext{
${ }^{2}$ For the two participants who had only experienced hearing a voice once, the first and last experiences were the same (although they still provided two sets of ratings). Excluding the data for these two participants from the analysis did not materially affect the results.

${ }^{3}$ Although this value is a little on the high side (cf. Slade \& Bentall, 1988), it is by no means at variance with previous findings using similar samples (e.g. Barrett \& Etheridge, 1992; Morrison, Wells, \& Nothard, 2000).
} 
hearing voices and the perception of voices were on the positive side of the rating scale midpoints (4.5). This applied to the psychotic group as well as to the 'normal' groups, although it should be noted that the psychotic group was a sample of remitted schizophrenics; a sample of acutely symptomatic schizophrenics may well have given negative ratings. These findings are consistent with a dimensional view of psychosis which sees psychosis not as separate from normality, but as merely an extreme along a continuum from normality to abnormality (Eysenck, 1992), and they are also consistent with the conclusion of Slade and Cooper (1979) that auditory hallucinations may be symptoms randomly distributed throughout the population. Nevertheless, affective reactions to hallucinations were found to differ significantly according to group. The psychotic group found the experience of hallucinations to be less positive than the control group who in turn found the experience to be less positive than the evangelical group.

The present findings on auditory hallucinations are somewhat at variance with the findings of Peters et al. (1999) on measures of delusional ideation. First, whereas Peters et al. found that levels of delusional ideation were similar in psychotic in-patients and members of new religious movements, the present study found significantly lower levels of auditory hallucination in evangelical Christians than in psychotic out-patients. Second, whereas Peters et al. found that the levels of distress associated with delusional ideation were similar in members of new religious movements and members of control groups, the present study found that the experience of auditory hallucinations was significantly more positive in evangelical Christians than in normal controls. There are several possible explanations for these differences. For example, Peters $e t$ al. investigated delusional ideation, whereas the present study examined the more specific issue of hearing voices. Another possibility concerns differences between the religious groups sampled. It could be argued that members of cults or new religious movements hold more extreme, unusual or idiosyncratic beliefs than members of evangelical Christian churches. The latter would tend to be regarded, at least by conventional majority group standards, as more socially acceptable than the former. In addition, it may be that evangelical Christians have access to better organized belief-validation and socialsupport systems than members of new religious movements, so that they are able to interpret and cope with their voices in a more positive fashion. Given the differences, however, between the Peters et al. study and the present study in terms of populations, samples and measures used, no clear conclusions can be drawn as to the reason for the differences in findings.

Some previous research has found that strong religious belief is associated with premorbid schizophrenia (e.g. Margolis \& Elifson, 1983; Spero, 1983). One possible explanation for the present findings is that those hearing voices in the non-psychotic groups are at a premorbid stage of psychoticism and they may subsequently go on to develop psychotic symptoms. However, the ages of the participants in the three groups were very similar, and, given that the average age of the non-psychotic groups was 33 years, it would not be expected that many would go on to develop psychosis after such a relatively late age.

In addition, if strong religious belief is an indicator of premorbid psychosis, it would be expected that the evangelical group would have experienced hallucinations in a similar way to the psychotic group. In fact, the affective reactions of the two groups were 
different - significantly more positive for the evangelical group than for the psychotic group. The findings for the evangelical group could be explained in two ways. On the one hand, they might interpret their initial experience of hearing voices in such a way that they attribute a positive religious meaning to it and they are therefore motivated to become members of an evangelical church in order to enhance their experience - a reinforcement explanation. On the other hand, their initial experience of voices may be negative or uncertain and they may join a church as a means of interpreting or coping with these experiences - a coping explanation. The support and guidance they receive from the church then allows them to subsequently interpret the voices in a positive light.

This latter explanation would predict that evangelicals' later experiences would be more positive than their initial experiences. In support of this, evangelicals reported their most recent experience to be more positive than their first experience. A similar type of explanation may apply to the psychotic group who also reported their most recent experience to be more positive than their first experience. Given that the psychotic group were sufficiently fit to attend day centres, it is likely that the psychiatric treatment they had received not only improved their general functioning but also their coping with voices. It should be noted here that the findings for affective reactions were stronger than the findings for perceptions of voices, in particular the difference between the groups in their evaluations of their first and last experiences was significant for rated feelings but not for perception of voices. An obvious explanation for this latter finding is that one's perceptions of an (apparently) external stimulus are less susceptible to change over time than one's internal affective reactions to it.

As mentioned earlier, an alternative, and perhaps more parsimonious, explanation is that both the evangelical and psychotic groups had become habituated to their hallucinations with repeated experiences of hearing voices. However, although more parsimonious, on closer examination this explanation does not seem to account for the findings. An habituation explanation would predict that an individual's feelings or perceptions would become less extreme after repeated experiences, whereas the findings show that the feelings of the psychotic and evangelical individuals became more extreme from first to last experience. That is, the subjective ratings of the last experience moved away from the scale mid-point towards the positive end of the scale.

The present study cannot distinguish between these different explanations. What is needed is longitudinal research that assesses the experience of hallucinations at various points in time - for example, at the start of joining an evangelical group or at the start of treatment, at termination of membership of an evangelical group or psychiatric treatment, and at follow-up some time later. What is also needed is more detailed information on people's experiences of hearing voices. The present study is limited in its rather narrow focus on a self-rating methodology. More open-ended interview methods can perhaps provide a better picture of the multifaceted nature of hallucinatory experiences (e.g. Jackson, 1997; Jackson \& Fulford, 1997).

In general, if evangelical churches serve a therapeutic as well as a religious function, then it would be expected that the positive support and feedback received from a community of worshippers would serve to ameliorate any negative experiences associated with hallucinations (cf. Crossley, 1995; Romme, Honig, Noorthoorn, \& Escher, 1992). Studies of psychotic individuals have shown that focusing on the meaning of 
hallucinations can have a beneficial effect for sufferers of persistent auditory hallucinations through a reinterpretation of beliefs about voices (e.g. Chadwick \& Birchwood, 1994; Chadwick, Birchwood, \& Trower, 1996). Such studies of psychotic groups might shed some interesting light on the experiences of evangelical groups and vice versa.

\section{References}

Al-Issa, I. (1978). Social and cultural aspects of hallucinations. Psychological Bulletin, 84, 570-587.

Andrade, C. (1988). True hallucinations as a culturally sanctioned experience. British Journal of Psychiatry, 152, 838-839.

American Psychiatric Association. (1987). Diagnostic and statistical manual of mental disorders (3rd ed., rev.). Washington, DC: APA.

Barrett, T. R., \& Etheridge, J. B. (1992). Verbal hallucinations in normals - I: People who hear 'voices'. Applied Cognitive Psychology, 6, 379-387.

Bentall, R. P. (1990). The illusion of reality: A review and integration of psychological research on hallucinations. Psychological Bulletin, 107, 82-95.

Bentall, R. P., \& Slade, P. D. (1985). Reliability of a scale measuring disposition towards hallucination. Personality and Individual Differences, 6, 527-529.

Bhugra, D. (1996). Psychiatry and religion. London: Routledge.

Buckley, P., \& Galanter, M. (1979). Mystical experience, spiritual knowledge and a contemporary ecstatic religion. British Journal of Medical Psychology, 52, 281-289.

Chadwick, P., \& Birchwood, M. (1994). The omnipotence of voices: A cognitive approach to auditory hallucinations. British Journal of Psychiatry, 164, 190-201.

Chadwick, P., Birchwood, M., \& Trower, P. (1996). Cognitive therapy for delusions, voices and paranoia. Chichester: Wiley.

Claridge, G. (1985). Origins of mental illness. Oxford: Blackwell.

Claridge, G. (1994). Single indicator of risk for schizophrenia: Probable fact or likely myth? Schizophrenia Bulletin, 20, 151-168.

Close, H., \& Garety, P. (1998). Cognitive assessment of voices: Further developments in understanding the emotional impact of voices. British Journal of Clinical Psychology, 37, 173-188.

Crossley, D. (1995). Religious experience within mental illness. British Journal of Psychiatry, 166, 284286.

David, A. S. (1994). The neuropsychological origin of auditory hallucinations. In A. S. David \& J. C. Cutting (Eds.), The neuropsychology of schizophrenia. London: Erlbaum.

Esquirol, J. E. D. (1832). Sur les illusions des sens chez alienes [On the sensory illusions of the insane]. Archives Generales de Medicine, 2, 5-23.

Eysenck, H. J. (1992). The definition and measurement of psychoticism. Personality and Individual Differences, 13, 757-785.

Frith, C. D. (1992). The cognitive neuropsychology of schizophrenia. London: Erlbaum.

Fulford, K. W. M. (1989). Moral theory and medical practice. Cambridge: Cambridge University Press.

Garety, P. A., \& Hemsley, D. R. (1987). Characteristics of delusional experience. European Archives of Psychiatry and Neurological Science, 236, 294-298.

Garety, P. A., \& Hemsley, D. R. (1994). Delusions: Investigations into the psychology of delusional reasoning. Oxford: Oxford University Press.

Green, P., \& Preston, M. (1981). Reinforcement of vocal correlates of auditory hallucinations by auditory feedback: A case study. British Journal of Psychiatry, 139, 204-208.

Hefferline, R. F., Bruno, L. J., \& Camp, J. A. (1971). Hallucinations: An experimental approach. In F. J. McGuigan \& R. A. Schoonover (Eds.), The psychophysiology of thinking: Studies of covert processes. New York: Academic Press.

Heilbrun, A. B. (1980). Impaired recognition of self-expressed thoughts in patients with auditory hallucinations. Journal of Abnormal Psychology, 89, 728-736.

Hemsley, D. R. (1993). A simple (or simplistic) cognitive model for schizophrenia. Behavioural Research and Therapy, 31, 633-645. 
Hoffman, R. E. (1986). Verbal hallucinations and language production processes in schizophrenia. The Behavioural and Brain Sciences, 9, 503-548.

Hood, R. W. (1973). Religious orientation and the experience of transcendence. Journal of Scientific Studies of Religion, 12, 441-448.

Jackson, M. C. (1997). Benign schizotypy? The case of spiritual experience. In G. S. Claridge (Ed.), Schizotypy: Relations to illness and health. Oxford: Oxford University Press.

Jackson, M. C., \& Fulford, K. W. M. (1997). Spiritual experience and psychopathology. Philosophy, Psychiatry and Psychology, 4, 41-65.

James, W. (1902). The varieties of religious experience. New York: Longmans.

Jaspers, K. (1911). Zur analyse der trug wahrnehmunger (leibhaftigkeit und realitatsurteil) [On the analysis of deceptive perceptions (physicality and the judgement of reality)]. Zeitschrift fur die gesamte Neurologie und Psychiatrie, 6, 460-535.

Johnson, F. H. (1979). The anatomy of hallucinations. New York: Nelson Hall.

Launay, G., \& Slade, P. D. (1981). The measurement of hallucinatory predisposition in male and female prisoners. Personality and Individual Differences, 2, 221-234.

Margolis, R. D., \& Elifson, K. W. (1983). Validation of a typology of religious experience and its relationship to the psychotic experience. Journal of Psychology and Theology, 11, 135-141.

Miller, L. J., O'Connor, E., \& Di Pasquale, T. (1993). Patients' attitudes toward hallucinations. American Journal of Psychiatry, 150, 584-588.

Mintz, S., \& Alpert, M. (1972). Imagery vividness, reality testing, and schizophrenic hallucinations. Journal of Abnormal Psychology, 19, 310-316.

Morrison, A. P., \& Haddock, G. (1997). Cognitive factors in source monitoring and auditory hallucinations. Psychological Medicine, 27, 669-679.

Morrison, A. P., Wells, A., \& Nothard, S. (2000). Cognitive factors in predisposition to auditory and visual hallucinations. British Journal of Clinical Psychology, 39, 67-78.

Peters, E., Day, S., McKenna, J., \& Orbach, G. (1999). Delusional ideation in religious and psychotic populations. British Journal of Clinical Psychology, 38, 83-96.

Preuss, J. (1975). Mental disorders in the Bible and Talmud. Israeli Annals of Psychiatry and Related Disciplines, 13, 221-238.

Prince, R. H. (1992). Religious experience and psychopathology: Cross-cultural perspectives. In J. F. Schumaker (Ed.), Religion and mental health. New York: Oxford University Press.

Romme, M. A. J., Honig, A., Noorthoorn, E. O., \& Escher, A. D. (1992). Coping with hearing voices: An emancipatory approach. British Journal of Psychiatry, 161, 99-103.

Schneider, K. (1959). Clinical psychopathology. New York: Grune \& Stratton.

Slade, P. D., \& Bentall, R. P. (1988). Sensory deception: A scientific analysis of hallucinations. London: Croom Helm.

Slade, P. D., \& Cooper, R. (1979). Some conceptual difficulties with the term 'Schizophrenia': An alternative model. British Journal of Social and Clinical Psychology, 18, 309-317.

Spero, M. H. (1983). Religious patients in psychotherapy. British Journal of Medical Psychology, 56, 287291.

West, L. J. (1962). A general theory of hallucinations and dreams. In L. J. West (Ed.), Hallucinations. New York: Grune \& Stratton. 